\title{
Correction to: Prosthesis design influences segmental contribution to total cervical motion after cervical disc arthroplasty
}

\author{
Avinash G. Patwardhan ${ }^{1,2}\left[\right.$ Robert M. Havey ${ }^{1}$
}

Published online: 17 September 2020

c) Springer-Verlag GmbH Germany, part of Springer Nature 2020

\section{Correction to: European Spine Journal} https://doi.org/10.1007/s00586-019-06064-4

Unfortunately, Figs. 1 and 2 have been incorrectly published in the original publication. The complete correct figures are given below with the captions.

The original article has been updated.

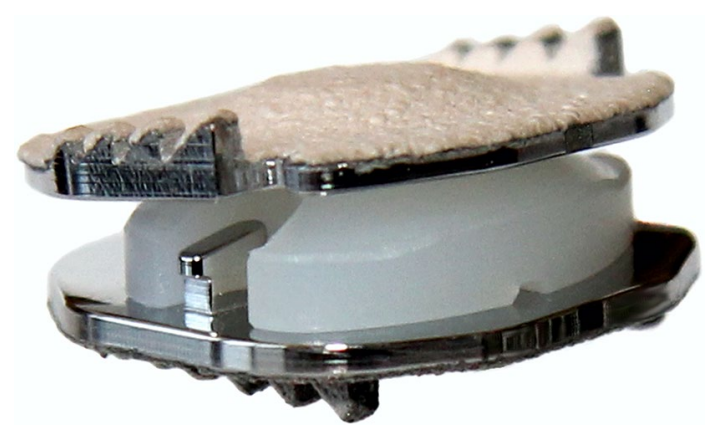

Fig. 1 Mobi-C® is a cervical disc prosthesis with three components articulating in two bearings. The bearing (joint) formed by the mobile core with the superior prosthetic endplate is spherical. The core forms a planar bearing with the inferior prosthetic endplate. Zimmer Biomet, Inc., Warsaw, IN, USA

The original article can be found online at https://doi.org/10.1007/ s00586-019-06064-4.

Avinash G. Patwardhan

apatwar@lumc.edu

1 Musculoskeletal Biomechanics Laboratory, Edward Hines, Jr. VA Hospital, Hines, IL, USA

2 Department of Orthopedic Surgery and Rehabilitation, Loyola University Medical Center, 2160 S. First Avenue, Maywood, IL 60153, USA

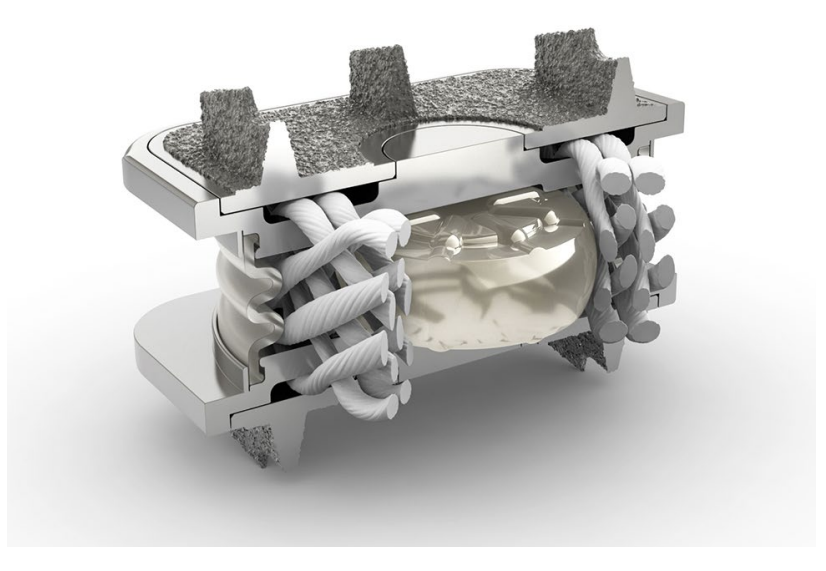

Fig. 2 The M6-C ${ }^{\text {TM }}$ is a non-articulating cervical disc prosthesis with a compressible core and artificial fibre annulus. Figure courtesy of Orthofix Inc., Lewisville, TX, USA

Publisher's Note Springer Nature remains neutral with regard to jurisdictional claims in published maps and institutional affiliations. 